\title{
Propagação in vitro de copo-de-leite: sulfato de adenina e 6-benzilaminopurina ${ }^{(1)}$
}

\author{
MÁRCIA DE NAZARÉ OLIVEIRA RIBEIRO (2), MOACIR PASQUAL (3), ADRIANO BORTOLOTTI DA SILVA (4) \\ e VANTUIL ANTÔNIO RODRIGUES ${ }^{(5)}$
}

\begin{abstract}
RESUMO
O copo-de-leite [Zantedeschia aethiopica (L.) Spreng.], pertencente à família Araceae, é bastante apreciado tanto como flor de corte quanto na composição de jardins. Entretanto, a propagação convencional dessa espécie apresenta baixo rendimento. A cultura de tecidos, além de permitir rápida propagação clonal, também proporciona a obtenção de plantas uniformes e sadias. Sendo assim, o objetivo do trabalho foi estudar a influência de diferentes concentrações de 6-benzilaminopurina (BAP) e sulfato de adenina (SA) sobre o desenvolvimento in vitro de explantes de copo-de-leite. As culturas foram mantidas em meio MS acrescido de $\operatorname{BAP}(0,0 ; 8,9 ; 17,8$ e 26,7 $\mu \mathrm{M})$ e SA $(0,54,108$ e $162 \mu \mathrm{M})$ em arranjo fatorial $(4 \times 4)$. O material vegetal foi cultivado em sala de crescimento com temperatura de $27 \pm 1^{\circ} \mathrm{C}$, fotoperíodo de 16 horas, sob intensidade luminosa de $35 \mu \mathrm{mol} \mathrm{m} \mathrm{m}^{-2} \mathrm{~s}^{-1}$, por período de 60 dias. O delineamento experimental utilizado foi inteiramente casualizado, com quatro repetições, e a unidade experimental composta de três tubos de ensaio, sendo cada tubo constituído por um explante. A interação significativa entre os fatores BAP e SA ocorreu para número de folhas por explante $(4,8)$ e massa fresca da parte aérea $(0,73 \mathrm{~g}) \operatorname{com} 26,7 \mu \mathrm{M}$ de BAP e $108 \mu \mathrm{M}$ de SA. Para número de brotos obtidos por explante $(2,6)$ apenas o BAP apresentou significância na concentração de $22,19 \mu \mathrm{M}$. Os brotos apresentaram maior comprimento $(5,0 \mathrm{~cm})$ na ausência de BAP. A adição de BAP incrementou o número de brotos por explante. O emprego de sulfato de adenina em combinação com BAP teve efeito positivo para o acumulo de massa fresca e numero de folhas no cultivo in vitro.

Palavras-chave: Zantedeschia aethiopica, plantas ornamentais, cultura de tecidos.
\end{abstract}

\begin{abstract}
In vitro propagation of Calla lily: adenine sulphate and 6-benzilaminopurine

Calla lily [Zantedeschia aethiopica (L.) Spreng.] belonging to the Araceae family is appreciated as cut flower and in composition of gardens. However, the conventional propagation of this plants shows a poor productive. Thus, tissue culture besides allowing fast clonal propagation also provides healthy and uniforms plants. The aim was study the influence of the differents concentrations of 6-benzilaminopurine (BAP) and adenine sulphate (AS) on in vitro multiplication of Calla lily. The explants were maintained in MS medium added with $\operatorname{BAP}(0.0,8.9,17.8$ and $26.7 \mu \mathrm{M})$ and adenine sulphate $(0,54$, 108 and $162 \mu \mathrm{M})$. The plants were transferred to growth room and maintained at $25 \pm 1^{\circ} \mathrm{C}$ and photoperiod of 16 hours for 60 days, under luminous intensity of $35 \mu \mathrm{mol} \mathrm{m}{ }^{-2} \mathrm{~s}^{-1}$, for a period of 60 days. The experimental design was entirely randomized with four repetitions of three seedlings each, resulting in twelve plants per treatment, each tube with one plant. The statistics analysis showed interactive effects for quantify of BAP and AS for leaves number and fresh mass of the aerial parts. The highest number of leaves (4.8) and fresh mass of aerial parts $(0.73 \mathrm{~g})$ was obtained with $26.7 \mu \mathrm{M}$ of BAP combined with $108 \mu \mathrm{M}$ of AS, highest number of shoots (2.6) was obtained with $22,19 \mu \mathrm{M}$ of BAP and highest lengh of sprouts $(5.0 \mathrm{~cm})$ was observed in the absence of BAP. The addition of BAP increased the number of shoots per explant. The use of adenine sulphate in combination with BAP had a positive effect for the accumulation of fresh weight and number of leaves in vitro culture.
\end{abstract}

Keywords: Zantedeschia aethiopica, ornamental plants, tissue culture.

\section{INTRODUÇÃO}

As espécies do gênero Zantedeschia (família Araceae) são conhecidas popularmente, no Brasil, como copo-de-leite e internacionalmente como 'arum ou calla lily'(MARQUES et al., 2008). Esse táxon é considerado símbolo de pureza, sendo suas inflorescências muito apreciadas tanto na composição de jardins quanto para flor de corte. Elas, juntamente com suas folhagens, são muito utilizadas em arranjos florais (ALMEIDA e PAIVA, 2004).

Suas formas nativas ocorrem em terrenos úmidos e margens de lagos, sendo uma planta herbácea, entoucei- rada, rizomatosa e muito florífera (LORENZI e SOUZA, 2001; BRICKELL et al., 1996). A espécie Zantedeschia aethiopica (L.) Spreng. é a mais comercializada do seu gênero (ALMEIDA e PAIVA, 2004), apresentado folhas verdes de aspecto brilhante e flores brancas. No Brasil, na região Sudeste, a época de floração ocorre nos meses mais frios, entre maio e setembro (ALMEIDA e PAIVA, 2005). Além da espécie de flor branca, o gênero Zantedeschia possui outras seis: Z. rehmannii Engl., Z. jucunda Letty., Z. elliotiana (Watson) Engl., Z. pentlandii (Watson) Whittm., Z. albomaculata (Hook) Baill., Z.valida (Letty) Y. Singh. (SNIJDER e VAN TUYL, 2002; CHANG et al.,

\footnotetext{
(1) Trabalho recebido para publicação em 17/03/2011 e aprovado em 04/05/2014

(2) Doutora, Empresa de Pesquisa Agropecuária de Minas Gerais (EPAMIG), São João Del Rei-MG, Fazenda Experimental Risoleta Neves (FERN), Av.

Visconde do Rio Preto, s/n, Campus CTAN, 36301-360, E-mail: marcia 162@hotmail.com

(3) Professor Doutor do Departamento de Agricultura - UFLA.

(4) Professor Doutor do Departamento de Agronomia - UNIFENAS.

(5) Biólogo Laboratorista - UFLA
} 
2003). Atualmente, estão sendo comercializados híbridos entre diferentes espécies desse gênero, resultando na disponibilidade de genótipos com uma grande variabilidade de cores de flores. De maneira geral, a coloração possui tons que variam entre rosa, creme, amarelo, laranja e marrom (BROOKING e COHEN, 2002).

O método convencionalmente utilizado para propagação do copo-de-leite é por divisão de touceiras ou rizomas (SALINGER, 1991), o que pode favorecer a disseminação de agentes fitopatogênicos, tais como a bactéria Erwinia carotovora, causadora da principal doença da cultura, conhecida por podridão mole (GARCIA-GARZA et al., 2004), além do vírus do mosaico do inhame - DsVM (RIVAS, 2006). A produção de mudas de alta qualidade genética e isentas de fitopatógenos pode ser obtida por meio de técnicas de micropropagação (SEGEREN et al., 2003), sendo empregada especialmente em espécies de alto valor comercial como é o caso das flores e plantas ornamentais (DONINI, 2004). No entanto, o alto custo da muda micropropagada ainda é um fator limitante para o uso desse tipo de material propagativo pelos produtores rurais (MARQUES et al., 2008), sendo necessária a otimização do processo, sobretudo no ajuste dos fatores que induzem a multiplicação das plantas in vitro (PASQUAL, 2001), visando ganho em escala e redução dos custos de produção.

A 6-benzilaminopurina (BAP) é uma citocinina amplamente utilizada na micropropagação por ser relativamente de baixo custo e eficiente indutor de brotações durante a fase de multiplicação in vitro (KOECH et al., 2005; BRUM et al., 2002; ARAÚJO et al., 2004; GEORGE, 1996). Esse regulador de crescimento tem sido largamente empregado no estabelecimento in vitro da cultura e como indutor de brotações em copo-de-leite (CHANG et al., 2003; EBRAHIN, 2004; D'ARTH et al., 2002; CHEN et al., 2000).

O sulfato de adenina (SA) vem sendo utilizado como indutor do crescimento de brotações in vitro (GUERRA e NODARI, 2006), sendo seu efeito considerado semelhante ao de uma citocinina fraca. Quando em combinação com as citocininas presentes no meio de cultura pode aumentar a proliferação de brotações (SAMANTARY e MAITI, 2011; SIWACH e GILL, 2011; CALDAS et al., 1998). Na literatura, não constam dados sobre o efeito de SA na propagação micropropagação de copo-de-leite, entretanto, foram relatados efeitos positivos do seu emprego no crescimento in vitro de Costus speciosus (PUNYARANI e SHARMA, 2010), Chlorophytum arundinaceum (SAMANTARY e MAITI, 2011) e Ficus religiosa (SIWACH e GILL, 2011).

Dessa forma, este trabalho teve como objetivo avaliar o efeito do BAP e sulfato de adenina na propagação in vitro de Zantedeschia aethiopica.

\section{MATERIAL E MÉTODOS}

O trabalho foi realizado no Laboratório de Cultura de Tecidos Vegetais, do Departamento de Agricultura da Universidade Federal de Lavras (UFLA), Lavras, Minas Gerais.

O copo-de-leite [Zantedeschia aethiopica (L.) Spreng.] foi estabelecido in vitro a partir da cultura de ápices caulinares extraídos de plantas matrizes mantidas no Banco de Germoplasma do Setor de Floricultura do Departamento de
Agricultura (DAG/UFLA). Esses explantes foram inoculados em meio de cultura MS (MURASHIGE e SKOOG, 1962), suplementado com $9,0 \mu \mathrm{M}$ de 6-benzilaminopurina (BAP), acrescido de $30 \mathrm{~g} \mathrm{~L}^{-1}$ de sacarose, solidificado com 5,5 $\mathrm{g} \mathrm{L}^{-1}$ de ágar e com o $\mathrm{pH}$ ajustado para 5,8, antes da autoclavagem $\left(121^{\circ} \mathrm{C}\right.$ por 20 minutos). As culturas foram mantidas em sala de crescimento com temperatura de 27 $\pm 1^{\circ} \mathrm{C}$, sob $35 \mu \mathrm{mol} \mathrm{m} \mathrm{m}^{-2} \mathrm{~s}^{-1}$ de intensidade luminosa provenientes de lâmpadas brancas frias e fotoperíodo de 16 horas, por 30 dias.

Para a implantação do experimento, brotações obtidas, a partir dos ápices caulinares, foram subcultivadas por três vezes sucessivamente, no meio de cultura descrito anteriormente, visando a obtenção do número necessário de explantes. Antes da inoculação, os brotos foram uniformizados para $1 \mathrm{~cm}$ de comprimento e transferidos de acordo com os diferentes tratamentos.

Os tratamentos foram constituídos de concentrações de $\operatorname{BAP}(0,0 ; 8,9 ; 17,8$ e $26,7 \mu \mathrm{M})$ e sulfato de adenina - SA $(0,54,108$ e $162 \mu \mathrm{M})$ em todas as combinações possíveis. As culturas foram mantidas, tanto no meio de cultura básico quanto na sala de crescimento, nas mesmas condições descritas anteriormente.

Após o período de 60 dias de cultivo, foram realizadas avaliações quanto aos seguintes parâmetros: número e comprimento $(\mathrm{cm})$ de brotos por explante, número de folhas e massa fresca da parte aérea (g) por broto.

Os tratamentos foram dispostos em delineamento inteiramente casualizado, em arranjo fatorial $4 \times 4$, sendo quatro concentrações de BAP e quatro concentrações SA, com quatro repetições e a unidade experimental constituída de três tubos de ensaio contendo um explante cada, totalizando 12 tubos por tratamento. Os resultados foram submetidos à análise de variância, utilizando o software Sisvar (FERREIRA, 2000), com regressão linear e polinomial para concentrações de BAP e SA.

\section{RESULTADOS E DISCUSSÃO}

O número de brotos foi afetado diretamente pelas doses de BAP (Figura 1A), sendo o melhor resultado esperado com o uso de 22,19 $\mu \mathrm{M}$, atingindo 2,5 brotos por explante. MARQUES et al. (2008) registraram a produção de 2,3 brotos com o emprego de $4,44 \mu \mathrm{M}$ de BAP para copo-de-leite (Zantedeschia spp.) cultivar Neroli. RIBEIRO et al. (2009a) trabalhando com a mesma espécie estudada, verificaram maior número de brotos $(2,0)$ em meio de cultura contendo 22,19 $\mu \mathrm{M}$ de BAP e $45 \mathrm{~g} \mathrm{~L}^{-1}$ de sacarose. $\mathrm{KOECH}$ et al. (2005) observaram que o uso de $8,88 \mu \mathrm{M}$ de BAP induziu maior número de brotos por explante $(2,5)$ e maior comprimento de brotos $(3,7 \mathrm{~cm})$ em copo-de-leite (Zantedeschia albomaculata) após quatro semanas de cultivo in vitro. Esses resultados apontam valores muito próximos das taxas de multiplicação em distintas concentrações de BAP em plantas de Zantedeschia spp. Isso talvez se deva a variabilidade das espécies e cultivares presente no gênero em estudo.

O regulador de crescimento BAP vem sendo empregado visando à indução de brotações em antúrio (Anthurium andraeanum Lind.), planta também pertencente à família Araceae (VARGAS et al., 2004), entre outras espécies, por 

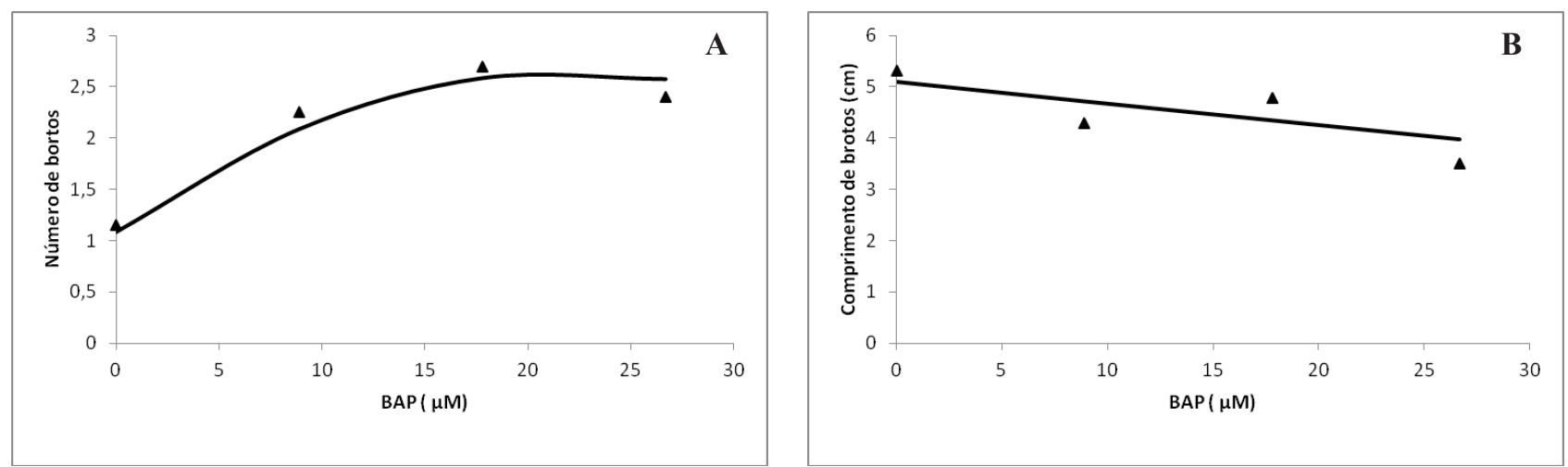

$Y=-0,0032 \times 2+0,1418 x+1,08 R 2=92 \%$

$Y=-0,042 x+5,09 \quad R 2=78 \%$

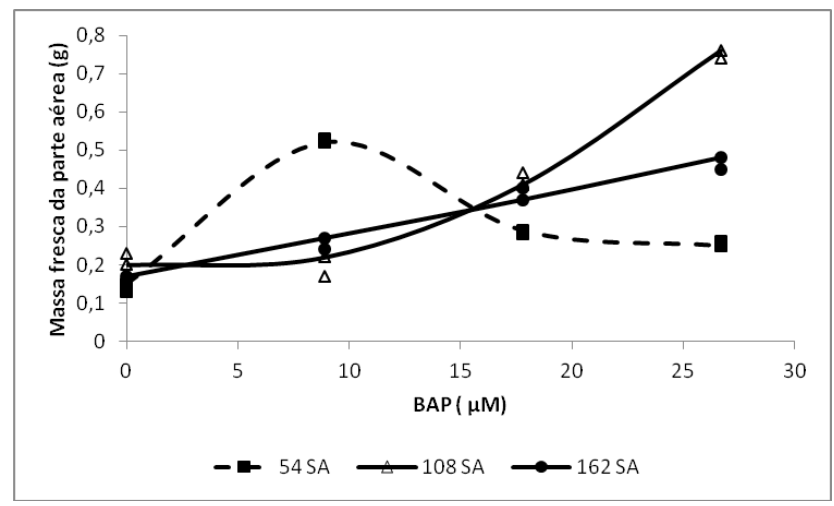

$\mathrm{Y} 54=0,00018 \mathrm{x} 3-0,008 \mathrm{x} 2+0,103 \mathrm{x}+0,15 \mathrm{R} 2=93 \%$

$\mathrm{Y} 108=0,0010 \mathrm{x} 2-0,0072 \mathrm{x}+0,20 \quad \mathrm{R} 2=87 \%$

$\mathrm{Y} 162=0,0112 \mathrm{x}+0,176 \mathrm{R} 2=82 \%$

Figura 1. Propagação in vitro de copo-de-leite [Zantedeschia aethiopica (L.) Spreng.] em função da concentração de 6-benzilaminopurina (BAP) e de sulfato de adenina (SA), aos 60 dias de cultivo em meio MS. A) Número de brotos por explante em função das diferentes concentrações de BAP; B) Comprimento de brotos (cm) em função das diferentes concentrações de BAP; C) Numero de folhas em função das diferentes concentrações de BAP e SA; D) Massa fresca da parte aérea (g) em função das diferentes concentrações de BAP e SA. Concentrações de SA em $\mu$ M. UFLA, Lavras-MG, 2007.

Figure 1. In vitro propagation of Calla lily [Zantedeschia aethiopica (L.) Spreng.] as a function of concentration of 6-benzylaminopurine (BAP) and adenine sulphate (AS), after 60 days of culture on MS medium. A) number of shoots per explant as a function of different concentrations of BAP; B) Length of sprouts (cm) as a function of different concentrations of BAP; C) Number of leaves as a function of different concentrations of BAP and AS; D) Fresh mass of the aerial part ( $g$ ) as a function of different concentrations of BAP and AS. AS concentrations in $\mu$ M. UFLA, Lavras, MG, 2007.

ser eficiente na multiplicação de plantas in vitro e relativamente de baixo custo (GEORGE, 1996). Entretanto, o número de brotos por explante $(2,5)$ verificado no presente trabalho, pode ser considerado relativamente inferior quando comparado com o do antúrio que é de 4,0 brotos por explante em média (LIENDO e MOGOLLÓN, 2009; VARGAS et al., 2004).

O SA é utilizado no crescimento de brotações ou como uma citocinina fraca, e em combinação com citocininas adicionadas ao meio de cultura visa à proliferação de brotos (SAMANTARY e MAITI, 2011; SIWACH e GILL, 2011; GUERRA e NODARI, 2006). Porém, no presente o estudo não houve efeito positivo do emprego de SA no incremento do número de brotos de Zantedeschia aethiopica. Novos trabalhos testando o emprego de outras fontes de citocininas, na presença ou ausência de SA, ou talvez testando-se outras concentrações, podem melhorar a proliferação de brotos em copo-de-leite. CHANG et al.(2003), em trabalho com Zantedeschia aethiopica obtiveram 3,2 brotos por explante com o emprego de 1-fenil-3-(1,2,3-tiadiazol-5-il) ureia (TDZ).

Para a variável comprimento de brotos (Figura 1B), o tratamento na ausência de BAP foi superior numericamente, quando comparado aos demais. Ou seja, com o 
aumento da concentração de BAP houve diminuição do comprimento dos brotos. Resultado semelhante foi observado por LIENDO e MOGOLLÓN (2009), esses autores verificaram redução no comprimento dos brotos em antúrio com o aumento da concentração de BAP. RIBEIRO et al. (2009b), trabalhando com a mesma espécie estudada, obtiveram comprimento de brotos de $2,2 \mathrm{~cm}$, em meio de cultura suplementado com $22,19 \mu \mathrm{M}$ de BAP, valor muito inferior quando comparado aos $4,5 \mathrm{~cm}$ de comprimento obtido no presente trabalho com o uso da mesma concentração de BAP (Figura 1B). As citocininas utilizadas na propagação in vitro de plantas apresentam efeito ananizante, reduzindo as distâncias entre nós e a altura das plantas produzidas durante a fase de multiplicação. E, por essa razão, para a maioria das espécies micropropagadas, é necessária uma fase de enraizamento/alongamento em meio de cultura na ausência de reguladores de crescimento ou na presença de auxinas (CALDAS et al., 1998; GEORGE, 1996; DEBERGH, 1994).

D'ARTH et al. (2002) afirmaram que o uso de doses elevadas de BAP, acima de $13,3 \mu \mathrm{M}$, na propagação in vitro de copo-de-leite pode levar a redução do comprimento do sistema radicular em até $80 \%$, durante o processo de aclimatização, quando comparado ao das brotações advindas de cultivo in vitro na ausência de BAP, devido basicamente ao efeito residual desse regulador de crescimento após o cultivo in vitro.

Para a variável número de folhas, houve significância para a interação concentração de BAP e SA. O melhor resultado foi observado com $26,7 \mu \mathrm{M}$ de BAP em combinação com $108 \mu \mathrm{M}$ de SA, atingindo 4,8 folhas por broto (Figura 1C). RIBEIRO et al. (2009b) registraram 1,32 folhas em plantas da mesma espécie estudada, em meio de cultura contendo 22,19 $\mu \mathrm{M}$ de BAP. Provavelmente, o SA em combinação com BAP promoveu maior número de folhas, o que possibilita a formação de mais gemas axilares e internódios na espécie em estudo, resultando no aumento do número de segmentos nodais e, consequentemente, maior taxa de multiplicação durante o processo de subcultivo.

Maior massa fresca da parte aérea $(0,74 \mathrm{~g})$ foi observada na concentração de $26,7 \mu \mathrm{M}$ de BAP em combinação com $108 \mu \mathrm{M}$ de SA (Figura 1D). Não foi observada, para a maioria dos tratamentos, a diminuição da massa fresca da parte aérea em função do aumento das concentrações de BAP (Figura 1D). Provavelmente, a presença de diferentes concentrações de SA, contribuiu de forma positiva para o maior acumulo de massa fresca, bem como de maior número de folhas (Figura 1C) de Zantedeschia aethiopica micropropagadas.

\section{CONCLUSÃO}

A taxa de multiplicação in vitro de Zantedeschia aethiopica é efetiva com o aumento da concentração de BAP. O emprego de sulfato de adenina isolado ou em combinação com BAP, no meio de cultura, não incrementa o número e o comprimento de brotos.

\section{REFERÊNCIAS}

ALMEIDA, E. F. A., PAIVA P. D. O. Floricultura 2 cultivo de copo-de-leite. Lavras: Editora UFLA, 2004, 28p. (Texto Acadêmico).

ALMEIDA, E. F. A., PAIVA P. D. O. Cultivo de copo-de-leite. Informe Agropecuário, Belo Horizonte, v. 26, n. 227, p. 30-35, 2005.

ARAÚJO, A. G.; FIORINI, C. V. A; PASQUAL, M.; SILVA, A. B.; VILLA, F. Multiplicação in vitro de gloxínia (Sinningia speciosa Lood. Hiern.). Revista Ceres, Viçosa, v. 51, n. 293, p. 117-127, 2004.

BRICKELL, C.; ZUK, J.; ZUK, J. D. (eds). A-Z encyclopedia of garden plants. Alexandria: American Horticultural Society, 1996. 576p.

BROOKING, I. R.; COHEN, D. Gibberellin-induced flowering in small tubers of Zantedeschia 'Black Magic'. Scientia Horticulturae, Amsterdam, v. 95, n. 1/2, p. 6373, 2002.

BRUM, G. R.; SILVA, A. B.; PASQUAL, M. Efeito de diferentes concentrações de BAP e ANA na proliferação in vitro da figueira (Ficus carica L.). Ciência e Agrotecnologia, Lavras, suplemento especial, p. 1403-1409, 2002.

CALDAS, L. S., HARIDASAN, P., FERREIRA, M. E. Meios nutritivos. In: TORRES, A. C., CALDAS, L. S., BUSO, J. A. (eds.). Cultura de tecidos e transformação genética de plantas. Brasília: EMBRAPA/CNPH, 1998, p. $87-132$.

CHANG, H. S.;CHAKRABARTY, D.; HAHN, E. J.; PAEK, K. Y. Micropropagation of calla lily (Zantedeschia albomaculata) via in vitro shoot tip proliferation. In Vitro Cellular \& Developmental Biology - Plant, Wallingford, v. 39, n. 2, p. 129-134, 2003.

CHEN, J. J.; LIU, M. C.; HO, Y. H. Size of in vitro plantlets subsequent tuber production of acclimated calla lily. Hortscience, Alexandria, v. 35, n. 2, p. 290292. 2000.

D'ARTH, S. M.; SIMPSON, S. I.; SEELYE, J. F.; JAMESON, P. E. Bushiness and cytokinin sensitivity in micropropagated Zantedeschia. Plant Cell, Tissue and Organ Culture, Amsterdan, v. 70, n. 1, p. 113-118, 2002.

DEBERGH, P.C. In vitro culture of ornamentals. In: VASIL, I.K.; THORPE, T.A. (eds.). Plant cell and tissue culture. Dordrecht: Kluwer Academic Plublishers, 1994. p. $561-573$. 
DONINI , L. P. Preparo de lâminas foliares de Aráceas ornamentais: desinfestação e tratamento antioxidante. Pelotas: UFPel, 2004. 54p. Monografia (Bacharelado em Ciências Biológicas).

EBRAHIN, M. K. H. Comparison, determination and optimizing the conditions required for rhizome and shoot formation, and flowering of in vitro cultured calla explants. Scientia Horticulturae, Amsterdam, v. 101, n. 3, p. 305-313, 2004. FERREIRA, D. F. Análises estatísticas por meio do Sisvar para Windows versão 4.0. In: REUNIÃO ANUAL DA REGIÃO BRASILEIRA DA SOCIEDADE INTERNACIONAL DE BIOMETRIA, 45, São Carlos, SP, 2000. Anais... São Carlos: UFSCar, 2000, p. 255-258.

GEORGE, E. F. Plant propagation by tissue culture, part 1 - the technology, 2. ed. Edington: Exegetics Limeted, 1996, 1574p.

GARCIA-GARZA, J. A.; BLOM, T. J.; BROWN, W.; ROBERTS, D. P; SCHNEIDER, K.; FREISEN, M.; GOMBERT, D. Increased incidence of Erwinia soft-rot on calla lilies in the presence of phosphorus. European Journal of Plant Pathology, Dordrecht, v. 110, n. 3, p. 293-298, 2004.

GUERRA, M. P.; NODARI, R. O. Apostila de biotecnologia. Florianópolis: CCA/UFSC, 2006, 41p.

KOECH, A. A.; ISUTSA, D. K.; WU, Q. Explants, hormones and sucrose influence in vitro shoot regeneration and rooting of calla lily (Zantedeschia albomaculata L. Spreng.) 'Black Magic'. Journal of Agriculture, Science and Technology, Kenya, v. 7, n. 1, p. 53-66, 2005.

LIENDO, M.; MOGOLLÓN, N. Multiplicación clonal in vitro del antúrio (Anthurium andraeanum Lind. cv. Nicoya). Bioagro, Barquisimeto, v. 21, n. 3, p. 179-182, 2009.

LORENZI, H.; SOUZA, H. M. Plantas ornamentais no Brasil: arbustivas, herbáceas e trepadeiras. 4. ed. Nova Odessa: Instituto Plantarum, 2001. 1088p.

MARQUES, D. A.; SEGEREN, M. I.; SEGEREN, A. F.; CASTRO, L. M. Micropropagação de Zantedeschia spp.: otimização do proceso produtivo. Revista Brasileira de Horticultura Ornamental, Campinas, v. 14, n. 2, p. 179$186,2008$.

MURASHIGE, T.; SKOOG, F. A. A revised medium for rapid growth and bioassays with tobacco tissue cultures. Physiologia Plantarum, Copenhagen, v. 15, n. 3, p. 473497, 1962.

PASQUAL, M. Reguladores de crescimento. In: Meios de cultura. Lavras: UFLA/FAEPE, 2001, v. $\overline{1, p}$. 23-49.
PUNYARANI, K.; SHARMA, J. Micropropagation of Costus speciosus (Koen.) Sm. using nodal segment culture. Notulae Scientia Biologicae, Cluj-Napoca, v. 2, n. 1, p. 58-62, 2010.

RIBEIRO, M. N. O.; PASQUAL, M.; SILVA, A. B.; RODRIGUES, V. A. Multiplicação in vitro de copo-de-leite: espectros de luz e sacarose. Ciência Rural, Santa Maria, v. 39 , n. 8 , p. 2388-2393, 2009a.

RIBEIRO, M. N. O.; PASQUAL, M.; VILLA, F.; CAVALLARI, L. L. Desenvolvimento in vitro de copo-de-leite: efeito das concentrações de sacarose e ácido giberélico. Semina: Ciências Agrárias, Londrina, v. 30, n. 3, p. 575580,2009 b.

RIVAS, E. B. Viroses de plantas ornamentais e medidas de controle. In: REUNIÃO ITINERANTE DE FITOSSANIDADE DO INSTITUTO BIOLÓGICO - PLANTAS ORNAMENTAIS, 14, Pariquera-Açú, 2006. Anais... Pariquera-Açú, SP, 2006, p. 21-26.

SALINGER, E. P. Producción commercial de flores. Zaragoza: Acribia, 1991, 371 p.

SAMANTARY, S.; MAITI, S. Factors influencing rapid clonal propagation of Chlorophytum arundinaceum (Liliales: Liliaceae), an endangered medicinal plant. Revista de Biologia Tropical, San José, v. 59, n. 1, p. 435-445, 2011.

SEGEREN , M. I.; CAMPOS, K. J. P.; CORRÊA, M. G. S.; DIAS, J. C. S. Avaliações de fitossanidade de clones de orquídeas no laboratório Proclone. In: CONGRESSO BRASILEIRO DE FLORICULTURA E PLANTAS ORNAMENTAIS, 14.; CONGRESSO BRASILEIRO DE CULTURA DE TECIDOS, 1., Lavras, 2003. Resumos... Lavras, UFLA/FAEPE, 2003, p. 423.

SIWACH, P.; GILL, A. R. Enhanced shoot multiplication in Ficus religiosa L. in the presence of adenine sulphate, glutamine and phloroglucinol. Physiology and Molecular Biology of Plants, Lucknow, v. 17, n. 3, p. 271-280, 2011.

SNIJDER, R. C.; VAN TUYL, J. M. Evaluation of tests to determine resistence of Zantedeschia spp. (Araceae) to soft rot caused by Erwinia carotovora subsp. carotovora. European Journal of Plant Pathology, Dordrech, v. 108, p. $565-571,2002$.

VARGAS, T. E.; MEJÍAS, A.; OROPEZA, M.; GARCIA, E. Plant regeneration of Anthurium andreanum cv Rubrun. Electronic Journal of Biotechnology, Valparaiso, v. 7, n. 3, p. 282-286, 2004. 